\title{
La inscripción monumental del Tolmo de Minateda (Hellín, Albacete) y la génesis de un epígrafe
}

\author{
Lorenzo ABAD CASAL \\ Universidad de Alicante \\ lorenzo.abad@ua.es
}

\section{RESUMEN}

Presentamos el estado actual de la investigación sobre una inscripción monumental aparecida en El Tolmo de Minateda (Hellín, Albacete), casi con toda certeza la antigua Ilunum. La inscripción, datada a finales del año 9 a.C., hace referencia a una actuación edilicia, posiblemente la construcción de un muro y una puerta. Un hecho patrocinado por el propio emperador Augusto, gestionado por el legado provincial Lucio Domicio Ahenobarbo y costeado por los primeros duoviri de la ciudad.

Palabras clave: Tolmo de Minateda. Ilunum. Actividad edilicia. Muro. Puerta. Augustus. Ahenobarbus.

\section{The Monumental Inscription of El Tolmo de Minateda (Hellín, Albacete, Spain) and the Origin of an Epigraph}

\begin{abstract}
We explain the current status of the research on a monumental inscription discovered in El Tolmo de Minateda (Hellín, Albacete), which is almost certainly the old city of Ilunum. The inscription, which dates back to the end of the year $9 \mathrm{BC}$, refers to some sort of construction, possibly a wall and a gate. This was sponsored by the Emperor Augustus himself, managed by the legate of the province Lucius Domitius Ahenobarbus, and financed by the first duumviri of the city.
\end{abstract}

Key Words: Tolmo de Minateda. Ilunum. Construction activity. Wall. Gate. Augustus. Ahenobarbus.

Sumario: 1. El lugar. 2. La inscripción monumental. 3. Ilunum. 


\section{El lugar}

Desde el año 1998, un equipo de la Universidad de Alicante y del Museo de Albacete viene excavando el yacimiento de El Tolmo de Minateda, en el término municipal de Hellín, en Albacete. (Fig. 1) La actuación tuvo su origen en una riada que dejó al descubierto en la zona llamada El Reguerón la parte superior de unos sillares con letras pertenecientes a una inscripción monumental. El hecho de que en uno de ellos pudiera leerse $C A E S \cdot A$ indicaba que incluía la mención de un emperador ${ }^{1}$ (Fig. 2).

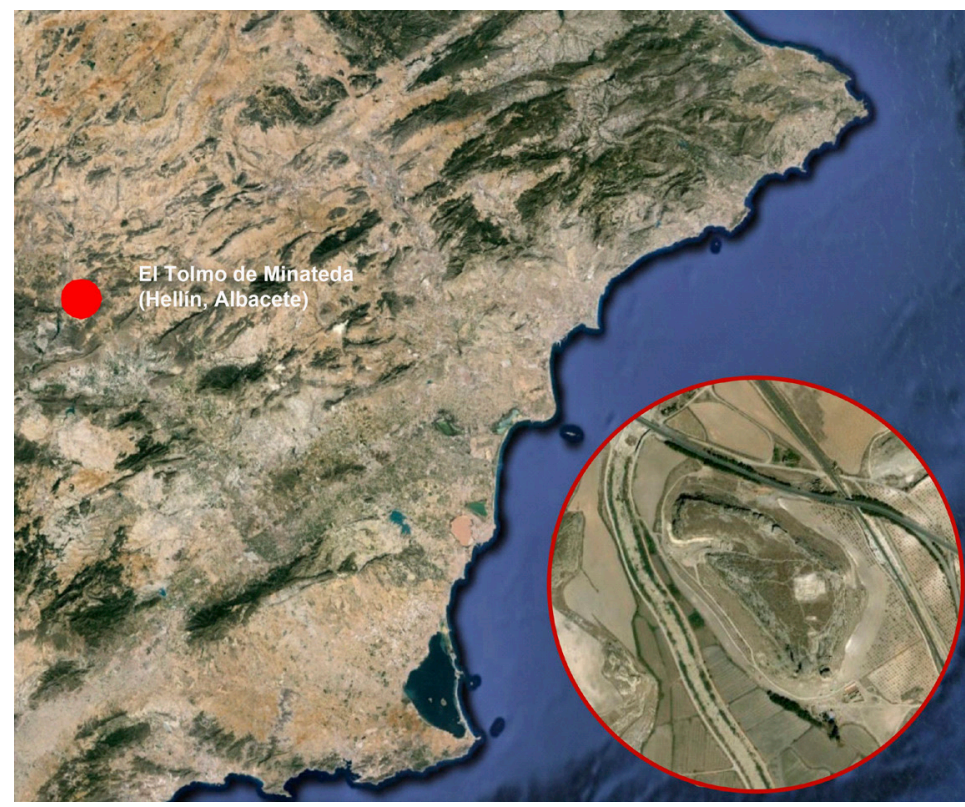

Fig. 1. Ubicación de El Tolmo de Minateda (Hellín Albacete) y vista aérea del yacimiento.

Los trabajos arqueológicos no resultaron fáciles. La pendiente de la vaguada en la que habían caído estos sillares, junto con los numerosos materiales de acarreo y las remociones y limpiezas realizadas a lo largo del tiempo, dificultaban la resolución de los problemas estratigráficos. Como curiosidad podemos indicar que encontramos huellas de una excavación realizada en 1942 por Antonio García y Bellido, Blas Taracena Aguirre y Joaquín Sánchez Jiménez. Este último fue quien excavó en esta zona, que abandonó al encontrar solo una acumulación de piedras. Hoy sabemos que se quedó a unos decímetros de los sillares y que esa acumulación de piedras era en realidad el relleno de una estructura defensiva. ${ }^{2}$

\footnotetext{
1 Sobre el tema hemos tratado en diversas ocasiones. Puede verse ABAD 1996, 77-108. ABAD 2006, 118 132. Abad - Abascal - SAnz 2002, 271-282, 271. Gutiérrez - Abad 2002, 133-143. Abad - SANZ 2012, $131-160$.

2 ABAD- GutiÉrReZ - SANZ 1998, 37-39.
} 


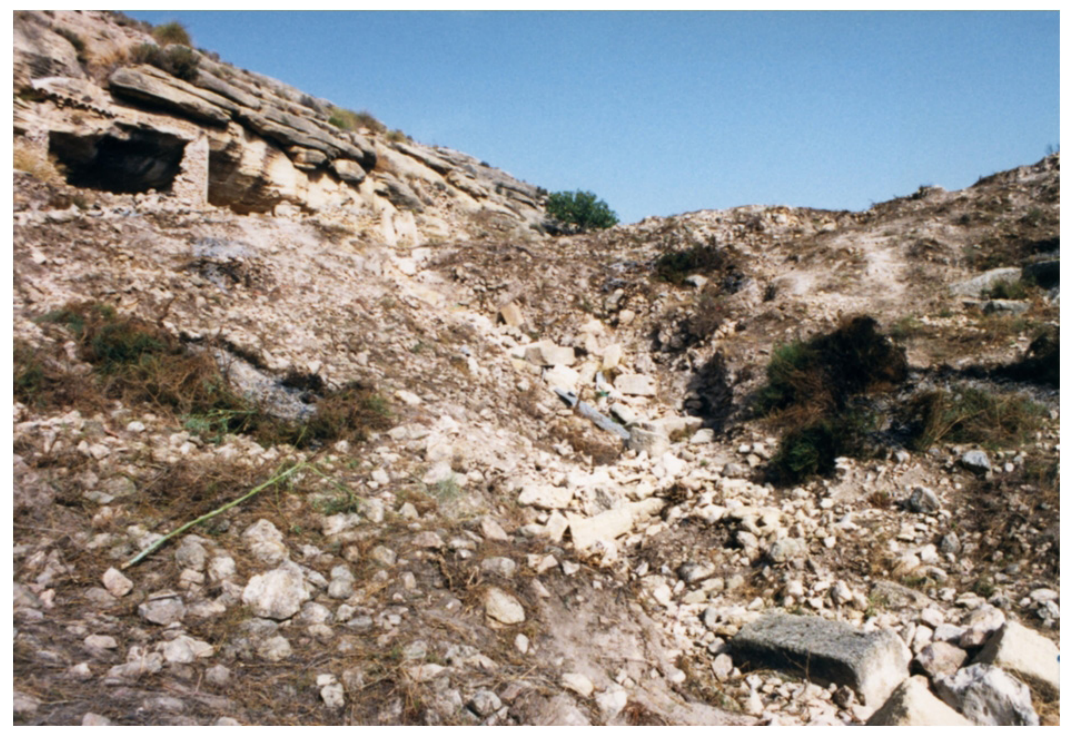

Fig. 2. Vista de El Reguerón inmediatamente antes de comenzar los trabajos, en septiembre de 1988.

Lo primero que encontramos fueron sillares, inscritos y no inscritos. Junto a los que contenían inscripción monumental había también varios epígrafes funerarios, todos de época altoimperial y con señales de haber estado insertos en una estructura. La argamasa cubría el campo epigráfico, por lo que resultaba evidente que el lugar del que habían caído no era su emplazamiento original. (Fig. 3) Aparecían también materiales como dovelas, fragmentos de cornisa y de fustes de columna. Especialmente significativa fue la presencia de una dovela de bóveda y un epígrafe funerario separados unos veinte $\mathrm{cm}$ pero con señales de haber estado unidos originalmente por medio de una grapa.

Poco tiempo después encontramos un muro, algo más al norte de la vaguada, que por técnica constructiva y materiales empleados era aquel en el que habían estado colocados todos estos sillares. Incorporaba materiales reaprovechados de diversa procedencia y desde luego no podía tratarse de la construcción original a la que hubiera pertenecido el epígrafe. Por detrás aparecía un relleno de piedras, en ocasiones aseguradas mediante lechadas de cal, que a veces se organizaban en una forma muy parecida al opus spicatum. La sospecha de que se trataba de un muro tardío quedó asegurada al estudiar en el laboratorio de la Universidad Autónoma de Madrid los morteros empleados, con un alto contenido de yeso. Estos estudios confirmaron que no podía tratarse de un mortero romano imperial, sino más bien altomedieval o, en todo caso, de época romana muy tardía.

Durante varios años prosiguieron las excavaciones en la vaguada. Lo siguiente en aparecer fue un sólido baluarte de mampostería ataludada, que en su parte superior mostraba huellas de un segundo cuerpo de adobe. Se trababa de una estructura sólida, 
de ancho irregular y rehecha en múltiples ocasiones, sobre todo por su cara interna, que se encontraba expuesta a la escorrentía de las aguas que bajaban por la vaguada. Un corte realizado en su interior proporcionó materiales ibéricos que llegaban al siglo I a.C., momento en el que debió de alcanzar la configuración hoy visible. Sin embargo, en su extremo septentrional, donde la roca subía y tuvo que ubicarse la puerta de acceso, se encontraron vestigios (restos de un muro de defensa o de abancalamiento, enterramientos...) que se remontaban a la Edad del Bronce. Nos encontrábamos, pues, ante una estructura que había tenido varios siglos de existencia y que había alcanzado su forma definitiva entre los siglos II y I a.C. Resultaba evidente que tampoco de esta estructura procedían los sillares con inscripción.

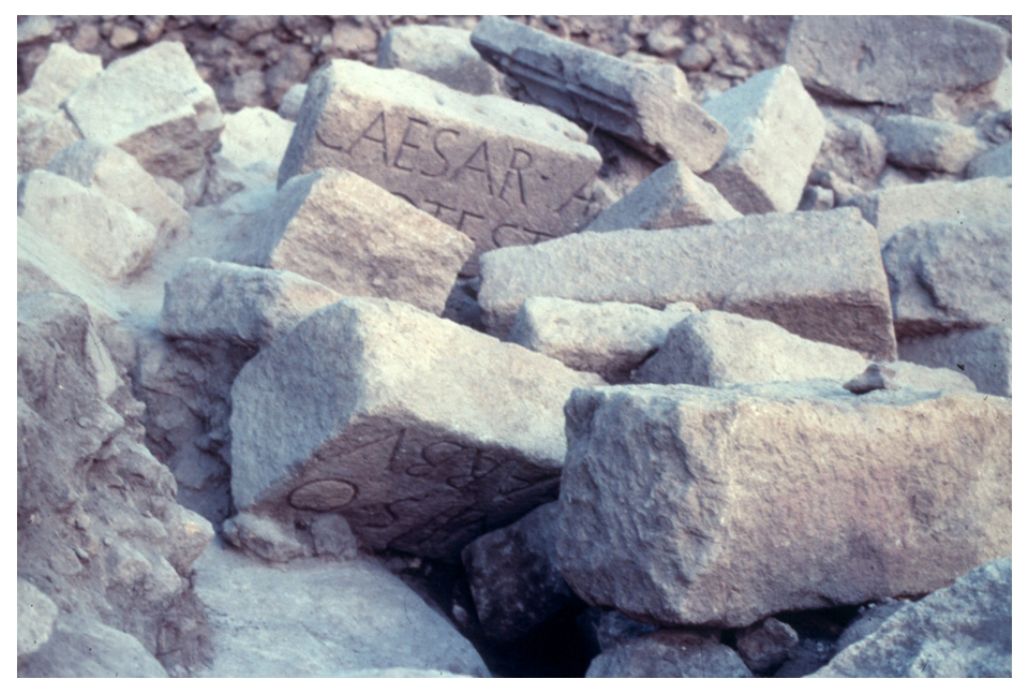

Fig. 3. Derrumbe sobre la vaguada de El Reguerón, lienzo occidental del baluarte visigodo.

Estábamos ante una reutilización, pero desconocíamos su ubicación original. Una torre de anclaje de una puerta, que habíamos limpiado unos metros más arriba, y que podría pertenecer a una estructura más antigua, resultó ser también parte del muro altomedieval.

Poco a poco íbamos recuperando la forma de esta muralla tardía. Se trataba de un baluarte en forma de L, que delimitaba un corredor entre uno de sus lados y el farallón rocoso de El Tolmo. Al fondo se abría la puerta, una estructura abovedada o por lo menos arqueada en parte, ya que al final del pasadizo se conservaba un salmer. El otro lado cortaba perpendicularmente la vaguada del Reguerón, formando una impresionante barrera que impedía el acceso a la ciudad. En el muro exterior se habían reutilizado los sillares con inscripción monumental y también los epígrafes funerarios. En el relleno interior, entre las piedras y la cal, aparecían aquí y allá completos o fragmentados, trozos de fuste, de capiteles, cimacios, frisos, retratos, morteros, esculturas funerarias... Pudimos identificar el lugar como aquél en el que en el año 1929, 
al hacer una conejera, se había encontrado el magnífico retrato que hoy se conserva en el Museo Arqueológico de Albacete. ${ }^{3}$

Pero ninguna información se obtenía acerca de la construcción a la que habían pertenecido los sillares con inscripción. La topografía del terreno hacía evidente que el emplazamiento era óptimo para que estos materiales hubieran formado parte de una estructura defensiva más antigua, pero nada se encontraba. Alguno de nuestros visitantes llegó a conjeturar que esos sillares habían sido traídos de otros lugares, y entre ellos barajaron la zona de Zama, al sur de El Tolmo, donde a principios de los años noventa se habían puesto al descubierto una gran balsa de recogida de agua y una estructura de opus signinum que sus excavadores interpretaron como el basamento de un templo. Se pensó que podía tratarse de una ciudad y que los sillares procedieran de su hipotética muralla. Sin embargo, un estudio de detalle de esos restos, que estuvieron visibles durante varios años, permitió comprobar que el supuesto templo formaba parte en realidad de una estructura de prensado y que lo que se veía, más que a una ciudad, parecía formar parte de una estructura tipo villa, o vicus, desarrollado al pie de la ciudad principal, que sería El Tolmo de Minateda. ${ }^{4}$

Tardamos aún varios años en resolver el enigma. Al profundizar la excavación entre la cara interior del muro altomedieval y la exterior del baluarte protohistórico, aparecieron finalmente, en la zona más próxima al camino de acceso a la ciudad unas huellas recortadas en la roca que habían servido como caja para asentar sillares. Estos habían desaparecido en ese lugar, pero se conservaban más al sur, conformando una línea paralela a la del muro altomedieval que había sido desmontada en buena parte. Al menos tres hiladas de sillería almohadillada eran observables in situ en la parte central, donde la vaguada era más profunda, en tanto que hacia el otro lado volvían a aparecer las cajas labradas en la roca hasta alcanzar el farallón meridional, donde eran visibles las mortajas para los sillares. Ninguno de ellos conservaba vestigios de inscripción, lo que era normal, ya que ésta tendría que estar en las hiladas superiores o, más bien, sobre la puerta de entrada. De ésta no se ha conservado nada, pues la zona fue limpiada a conciencia e incluso recortada cuando se construyó el último baluarte defensivo. La puerta romana debía de estar en el mismo sitio que la de éste, tal vez algo más adelantada, si formaba línea con la muralla, o más o menos en el mismo lugar, si ya entonces se contaba con un corredor de acceso protegido entre la roca y el baluarte ${ }^{5}$ (Fig. 4).

El misterio quedaba así desvelado, y se encontraron cosas curiosas. Por ejemplo, que los sillares romanos estaban siendo desmontados y algunos de ellos cortados en dos para que fueran más fáciles de trasladar. Seguramente esta muralla estaba ya en desuso desde hacía muchos años, algunas hiladas se habrían desmoronado y los visigodos -hoy sabemos que fueron ellos los autores del último baluarte- reutilizaron

3 Noguera 1994, 85-90.

4 ABAD - GutiÉRREZ - GAMO 1998, 89-91.

5 Parece más lógica la primera solución, acorde con la mayor parte de las puertas romanas. Sin embargo, al estar adosada al farallón rocoso de El Tolmo, podría suceder que se retranqueara con respecto a la línea exterior, como ocurre por ejemplo en la puerta de Sevilla de Carmona o en la acrópolis de Ferentino (cf. SCHATTNER 2006, 199-218, con bibliografía anterior). Esta es la solución que posteriormente se adoptó en el baluarte visigodo. 
todo lo que pudieron. Remontaron algunos sillares, extrajeron otros y los añadieron a epígrafes y restos de monumentos funerarios, acarreados desde su ubicación original a los lados de la vía que pasaba al pie del Tolmo, que unía Carthago Nova con Complutum.

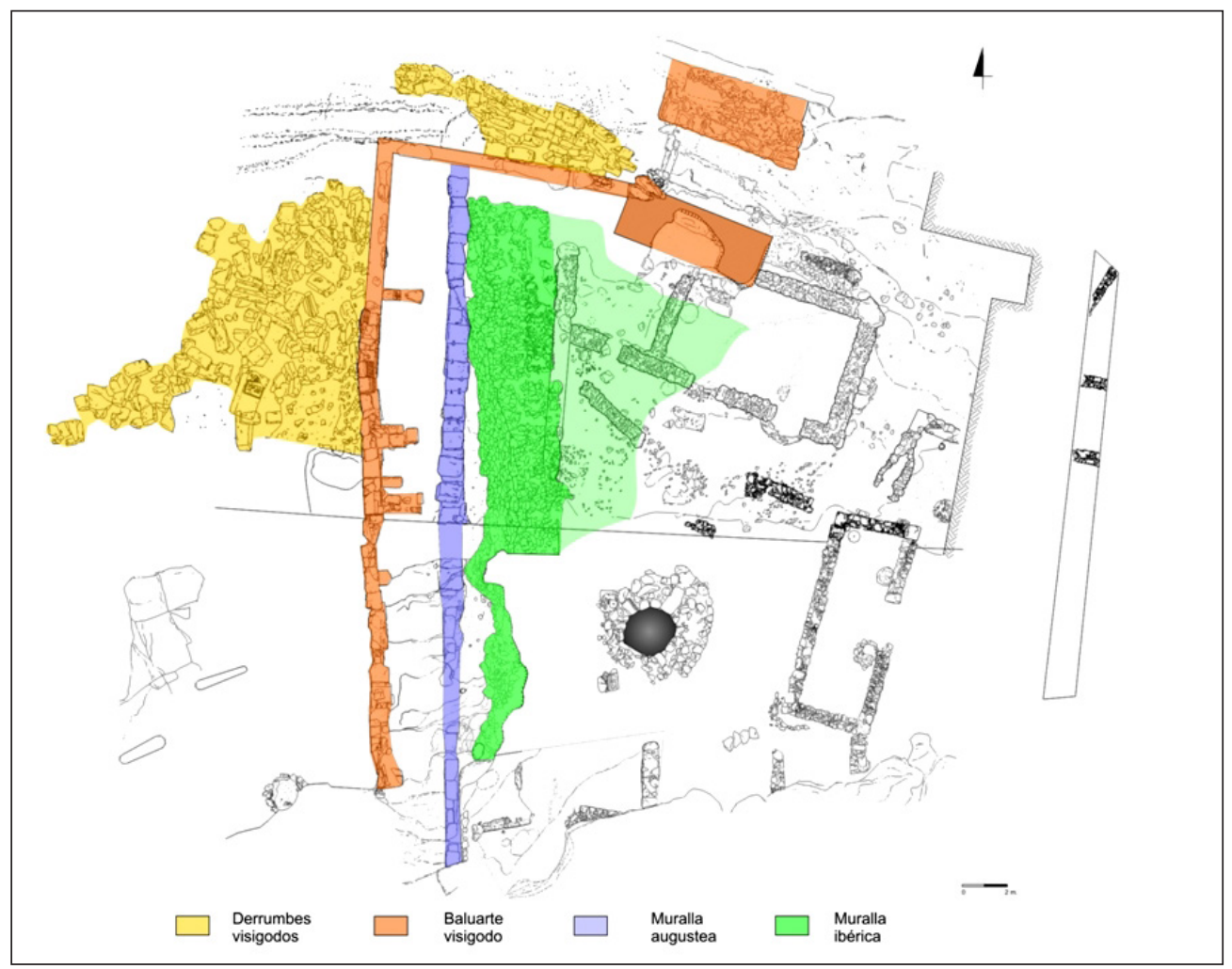

Fig. 4. Planta de las estructuras excavadas en 2011, último año de intervención.

Teníamos, por tanto, tres estructuras correspondientes a otros tantos momentos: un baluarte de mampostería con adobe en su parte superior, en uso entre finales del segundo milenio y los siglos II-I a.C.; un muro romano que debió ser visible durante varios siglos; y un baluarte visigodo construido en el siglo VI y arruinado poco después.

La técnica constructiva difiere mucho. No sólo la del baluarte protohistórico, que es de mampostería, sino también entre el muro romano y el baluarte visigodo. El primero está bien cimentado en la roca, al menos en toda la zona que hemos podido excavar. Sus sillares se disponen en seco, están bien trabajados y son de medidas homogéneas, unos con el doble de altura que otros. Los de las hiladas inferiores conservan aún el almohadillado rústico característico, en tanto los demás tienen todos sus lados lisos. En algunos casos están recortados por detrás y por los lados, para adaptarse a la cara delantera del baluarte protohistórico, que formaba dos curvas salientes y una contracurva. Cuando fue necesario se eliminaron las partes más salientes de 
éste, pero cuando el solapamiento era pequeño, como ocurre en el extremo norte, se recortaron los sillares para adaptarse a la estructura que tenían detrás. No hay ningún relleno estructural entre el muro romano y el baluarte protohistórico. Se rellenó de tierra y con los restos de talla de los propios sillares, que debieron tomar la forma definitiva al pie de la obra (Fig. 5).

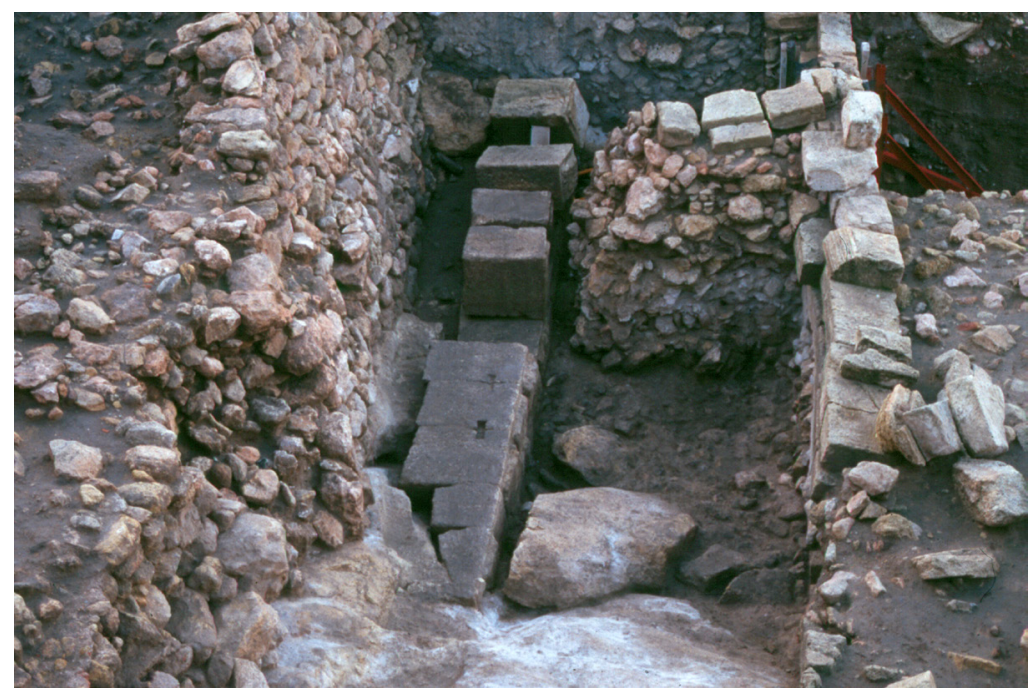

Fig. 5. De izquierda a derecha, baluarte protohistórico, muro romano y baluarte visigodo.

En cambio, la fábrica del muro visigodo es muy irregular, pues aprovecha sillares, epígrafes y piedras diversas de diferente grosor. Ello obliga a utilizar llagas irregulares de cal, a veces muy gruesas. Entre este muro y el romano se dispone un relleno de piedras, en ocasiones cogidas con cal, que recuerda el opus spicatum clásico. Cada cierto trecho, muro y relleno se cosen por medio de unos tirantes formados por sillares o lajas largas de piedra, uno de cuyos extremos estrechos aparece en el exterior del muro, a la manera de un tizón, en tanto que su lado largo se hunde en el relleno. Se trata de una técnica común en todo tiempo, y especialmente en construcciones tardías y de época bizantina, pero en este caso concreto adolece de los mismos defectos que hemos comentado al referirnos a la ejecución global del proyecto. Los sillares elegidos son o bien estelas alargadas de poca sección que no pueden resistir una fuerte tracción o bien están formados por la yuxtaposición de piedras independientes, colocadas una a continuación de otra, que no sirven para desempeñar esa función. El caso más llamativo es el de una dovela de bóveda unida con una grapa a un epígrafe funerario. En el momento de su aparición no entendíamos el motivo de esta disposición. Al identificar la estructura del muro pudimos comprenderlo en su totalidad.

La obra así dispuesta resultaba bastante débil y no debió de mantenerse en pie mucho tiempo. Cuando cayeron, los sillares se precipitaron en bloque hacia fuera. Los que cayeron sobre el camino lo hicieron en un ángulo de noventa grados con 
respecto a su posición en el muro, manteniendo incluso su disposición en hiladas, por lo que ha sido bastante fácil reponerlo en su forma original. (Fig. 6) Más difícil ha sido hacerlo con los que cayeron en el Reguerón, porque rodaron por la vaguada y sólo parcialmente mantuvieron la relación entre ellos. Además, algunos de los que cayeron primero fueron cubiertos por los que lo hicieron después, lo que ha impedido su recuperación. Es el caso, como luego veremos, de algunos de los que presentan inscripción.

La estructura se arruinó de un modo violento e instantáneo, lo que nos hace pensar que se debió a un movimiento sísmico. ${ }^{6}$ La sacudida no tuvo que ser necesariamente muy fuerte, ya que la mala cimentación del muro lo hacía candidato a una ruina inmediata. Al desplomarse hacia fuera, la cara externa del muro arrastró con ella las piedras del relleno. No olvidemos que ambas estructuras estaban trabadas por los tirantes y que parte de la piedra estaba cogida con capas de cal. El material del relleno se volcó hacia el exterior con los propios sillares, rellenando todos los intersticios y ocultándolos bajo una gruesa capa de piedra y argamasa deshecha. Esa capa es la que quedó en superficie, afectada luego por la erosión y la sedimentación de las aguas que bajaban por el Reguerón. En ella se encontró el retrato femenino en 1929 y con ella topó Joaquín Sánchez Jiménez en el año 42.

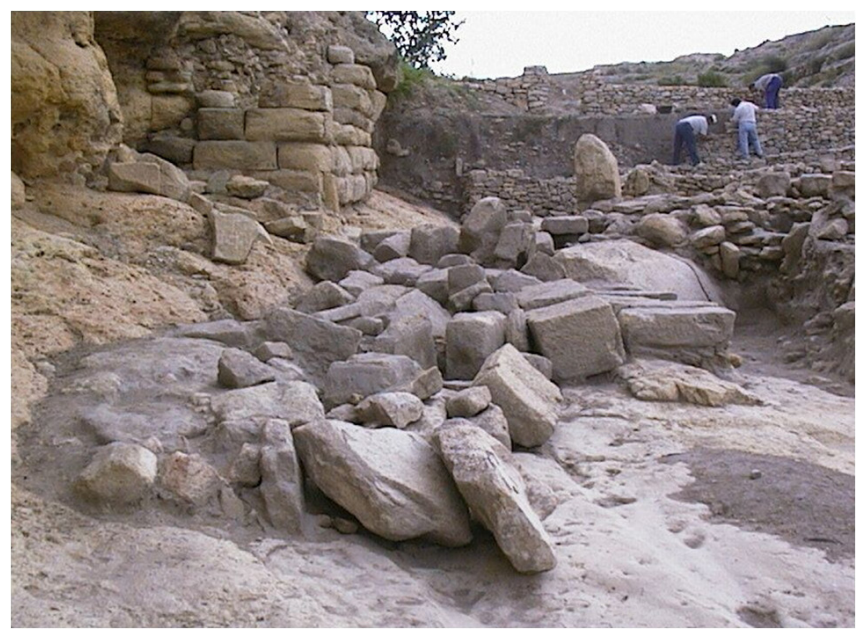

Fig. 6. Derrumbe sobre el camino de acceso, lienzo septentrional del baluarte visigodo.

Sin embargo, no toda la superficie del Reguerón tuvo la misma suerte. En la parte meridional, por fuera del baluarte visigodo, se había ido acumulando con los años una gruesa capa de detritus, un basurero en el que encontramos materiales arqueológicos anteriores y coetáneos, así como material diverso e incluso algún cráneo. Este basurero, que en el momento de iniciar nuestros trabajos alcanzaba prácticamente la cota de superficie, sirvió en su momento para amortiguar los efectos del movimiento

6 Rodríguez-Pascua ET aLII 2009, 110-113; Rodríguez-Pascua et ALII 2010, 1-14. 
sísmico, hasta tal punto que allí donde llegaba el basurero los sillares se conservaban prácticamente intactos.

\section{La inscripción monumental}

Como ya se ha indicado, el motivo de iniciar los trabajos, en octubre de 1988, fue la aparición en la vaguada del Reguerón de la parte superior de unos sillares con letras que parecían indicar la existencia de un epígrafe monumental dedicado a un emperador. En concreto se observaba la parte superior del sillar número 1, con las letras CAES - $A$. A lo largo de la primera campaña se encontraron casi todos los demás sillares con inscripción, en concreto el número 2, con la lectura $A N I S \cdot O / O B A R B V$, el número 3 , con la lectura $I M P \cdot$ y los números 4 y 5 , con la lectura $V D I O \cdot D R$. A diferencia de los tres sillares anteriores, estos últimos tenían aproximadamente la mitad de la altura y sólo contaban con una línea. IMP también tenía una sola línea, pero el sillar era de la misma altura que los de CAESAR y TANI y el texto estaba precisamente a la altura de la primera línea. (Fig. 7) Todas las letras tenían el mismo módulo y ductus, así que parecía evidente que se trataba de la misma inscripción. Del desarrollo del sillar número 1 podía colegirse que el nombre del emperador figuraba en dos líneas, y que la POTESTA inferior era el inicio de la segunda línea. Parecía evidente que nos encontrábamos ante un título imperial y que debíamos orientar nuestra búsqueda hacia un emperador de la dinastía julioclaudia, posiblemente el propio Augusto. La mención de $O B A R B V$ nos hacía mirar hacia un miembro destacado de esta familia.

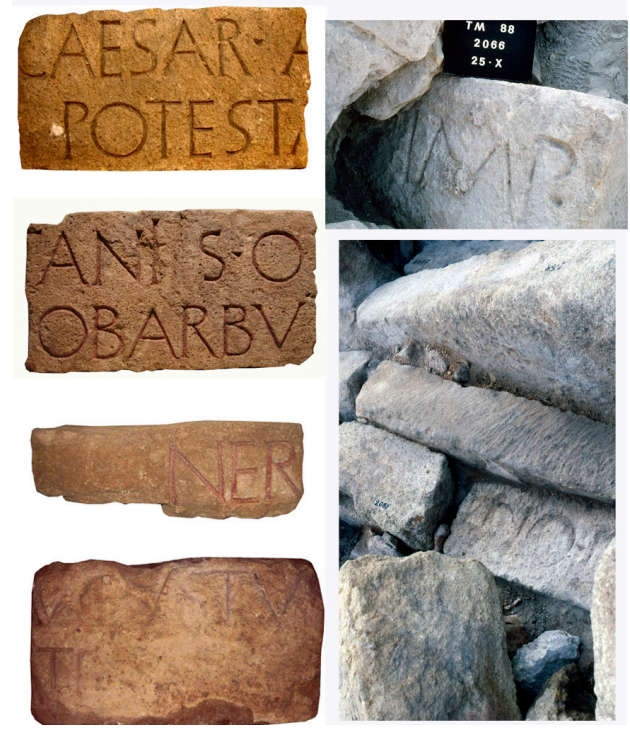

Fig. 7. Sillares con inscripción. A la izquierda, los que se han podido recuperar y se encuentran en el Museo de Albacete. A la derecha, los que aún se mantienen in situ. 
En la campaña siguiente, encontramos un nuevo sillar, esta vez entre los caídos del lienzo septentrional del baluarte visigodo. Sus dimensiones eran similares a los de $V D I O \cdot D R$ y presentaba la leyenda $N E R$ (número 6). (Fig. 7) El sillar tiene un recorte en su parte inferior izquierda, que parece realizada para engatillar con otro en su disposición originaria. La leyenda $N E R$, unida a $V D I O$ y a $D R$ en la misma línea, nos hizo pensar en la mención de un $\operatorname{Ner}$ (one) (Cl)audio $\operatorname{Dr}($ uso), e inmediatamente en la existencia de una datación consular. Estudiando los fasti consulares, encontramos que Nero Claudius Drusus fue cónsul en el año 9/8 a.C., junto con Titus Quinctius Crispinus. Eso nos proporcionaba una fecha absoluta para un acontecimiento que sin duda debía ser la inscripción monumental y lo que ella conmemorara.

En el año 1995, Javier López Precioso nos indicó que los encargados de realizar la prospección para la construcción de la autovía Albacete - Murcia a su paso por Hellín habían encontrado en el borde superior de una presa moderna, hoy aterrada, un sillar que podría corresponder a la inscripción que nos interesaba. Pudimos comprobar que se trataba de un sillar muy desgastado, pues se encontraba en el borde de la presa con la cara inscrita hacia arriba (número 7), pero conservaba lo suficiente como para comprobar que se trataba del sillar que seguía al de $C A E S A R \cdot A$. En la primera línea podía leerse $V G V S T V S$ (de la $\mathrm{S}$ final apenas una sombra) y en la segunda, mucho más desgastada, $T E \cdot X V \cdot C O$. Era evidente, por tanto, que nos encontrábamos ante el nombre de $I M P \cdot C A E S A R \cdot A V G V S T V S$ en el momento en que desempeñaba su $P O T E S T A T E \cdot X V$, lo que suponía la posibilidad de conocer su datación absoluta. Al cotejar esta fecha con la que se había presupuesto para los sillares con el nombre de Nero Claudius Drusus pudimos ver que ambas eran coincidentes, y que por tanto, la sospecha inicial de que el epígrafe se datara en los años 9/8 a.C. resultaba cierta. La publicación que en su momento realizamos permitía ya reconocer el nombre del emperador, así como el año de realización del epígrafe: Imperator Caesar Augustus, en su tribunicia potestate $X V$ y siendo cónsules Nero - Claudius · Drusus y Titus Quinctius $\cdot$ Crispinus.

Menos claro aparecía lo recogido en las dos líneas del sillar de $O B A R B U$. Era evidente que debía corresponder a una tercera y cuarta línea de la inscripción, ya que no tenía cabida en las dos primeras, delimitadas claramente por tribunicia del final de la primera y potestate de inicio de la segunda. Nuestra hipótesis fue sugerir que el TANI correspondiera a un gentilicio relacionado con el nombre de la ciudad, y que ésta podría ser la Ilunum citada por Ptolomeo y sin ubicación segura hasta el momento, ${ }^{7}$ aunque varios autores habían propuesto Hellín. Las letras $S O$ de la derecha planteaban más problemas, pues la primera estaba separada de TANI por una falla en la piedra. Nuestra propuesta fue entonces considerar ilunitani como un genitivo y relacionar la $S$ con la $O$ siguiente, de la que estaba separada por una interpunción. La línea inferior parecía mencionar claramente a un Ahenobarbus, que sólo podía ir en nominativo.

Cuando publicamos la inscripción, junto con el conjunto de epígrafes encontrados durante nuestras excavaciones en el yacimiento, ${ }^{8}$ propusimos, a partir de varios paralelos, que la inscripción podía hacer mención de un murum et portam y que tani debía

7 ALFÖLDY 1977, 91-92.

8 ABAD 1996. 
corresponder al gentilicio Ilunitani. ${ }^{9}$ Pensamos que formaría un conjunto, murum et portam municipi ilunitani, con un Imperator Augustus fecit, un Lucius Domitius Ahenobarbus faciendum curavit y una datación consular de Nero Claudio Druso y Tito Quinctio Crispino.

Estudios posteriores, en concreto de Géza Alföldy y de Juan Manuel Abascal, han precisado algunas de las hipótesis que en su momento mantuvimos, aportando nuevos puntos de vista que han sido aceptados por la comunidad científica y que si bien mantienen en lo esencial nuestras propuestas (año 9/8, mención de los ilunitani, mención de murum et portam) han ido más allá. ${ }^{10}$ La modificación principal está en el nombre de Augusto, que incorpora la mención de Imperator XIII y en el de L. Domitius Ahenobarbus, cuya titulatura se desarrolla de otra manera. Pero importante es sobre todo la interpretación que se hace del TANI SO que figura al principio de la segunda línea. En su interpretación, que creemos acertada, la rotura que existe en el sillar entre la i y la s se considera anterior a la labra de la propia inscripción, seguramente surgida en el momento de realizarla, debido a una falla de la piedra, una biocalcarenita local de no demasiada calidad. Esa rotura obligó al lapidario a separar dos letras, la i y la s, que en origen debían haber ido juntas, componiendo la forma tanis, seguramente la última parte del gentilicio Ilunitanis. De esta forma, la referencia a estos ciudadanos iría en dativo, lo que encaja mejor en el discurso de la inscripción que en nuestra primera versión, en genitivo.

Ello ha confirmado también la ubicación de dedit al final de la tercera línea, cuya redacción final ha experimentado varias propuestas, en función de que se incluyera el término insignem delante de fidem o no. Después de todo ello, la formulación de la inscripción que actualmente se maneja, y que ha sido dada como buena por la comunidad científica, es la siguiente (Fig. 8): ${ }^{11}$

Imp(erator) Caesar Augustus [pontifex maximus tribunicia]
potestate [XV c]o(n)s(ul) XI Imperator XIII murum et portam]
[iluni]tanis ob [fidem (?) eorum dedit]
[L(ucius) Domitius Ahe]nobarbu[s leg(atus) eius pro praetore dedicavit]
Ner[one Cl]audio $\cdot$ Druso [T(ito) Quinctio Crispino co(n)s(ulibus)]

9 Entre los epígrafes augusteos que aluden a concesiones similares podemos citar la de de Pax Iulia, en Portugal, del 3 a.C., interpretada como turres [et] portas... (AlarCÂO 1980, 46). La puerta de Fanum Fortunae, datada en 9 d.C., citaba un murum dedit (ILS 104; CIL XI, 6219; ReBECCHI 1987, 144 ss, fig. 19; BACChielli 1984, 79 s, lám. 43, 2. La de Nimes, del año 16 a.C. incluía portas muros [(que)] col(oniae) dat (CIL XII, 3151; Schulze 1909, 293, lám. xviii). Y también la de Zara (CIL III, 2907; ILS 5336), donde se lee murum et turris dedit. A ellas habría que añadir la de Arba (Croacia) datada en los años 11-10 a.C. y con la fórmula murum et turres dedit (Epigraphische Database Heidelberg, HD057998). Aunque la mención de turres es más frecuente que la de portam, en este caso concreto la inexistencia de torres y el que la inscripción se encontrara sobre la puerta de entrada nos hacen optar por esta opción.

10 AlFöLDY 2007, 341, nota 69 y fig. 2. Alföldy concreta la fecha en la segunda mitad del año 9, puesto que debe estar entre el 26 de junio del año 9, momento en que el emperador asume la XV Tribunicia Potestas y el 31 de diciembre de ese mismo año, fecha en que termina la datación consular.

11 AlFöLDY 2007, 341, nota 69 y fig. 2. 


\section{IMP CAESAR AVCVSTVSPONTIFEX-MAXIMVS TRIBVNICIA POTESTATEXVVCOS.XI.IMP.XIII.MVRVM ET PORTAM ILVNITANI/S.OB.FIDEM·EORVM · DEDIT L·DOMITIVS·AHENOBARBVSS.LEG.EIVS.PRO·PRAETORE·DEDICAVIT $\square$ NERONE.CLAVDIO-DRUSO-T.QVINCTIO.CRISPINO.COS}

Fig. 8. Restitución de la inscripción, según Alföldy, 2009. En rojo lo que se conserva en buen estado. En negro lo que puede restituirse con seguridad, ya sea en los propios sillares, ya sea sobre el papel. En azul, lo que aún puede estar sometido a discusión.

Se trata de todas formas de una hipótesis, ya que no se han encontrado los sillares que contuvieran la primera parte de la palabra ilunitanis ni tampoco la mención de murum et portam. En las campañas de los últimos años, que han descubierto la parte que faltaba del muro romano, no han aparecido nuevos sillares con inscripción. Es posible que algunos de ellos se encuentren en el muro de la presa donde se recuperó el que contiene la palabra Augusto, lo que hace por ahora difícil su recuperación.

\section{Ilunum}

Tema importante es el de la identificación con Ilunum. No hemos encontrado, entre las numerosas inscripciones conocidas en el lugar, ninguna que mencione expresamente este topónimo o su gentilicio. Como ya se ha indicado, Ilunum es una ciudad que aparece en la relación de Ptolomeo (Ptolomeo II 6.60) y que, junto con otras como Alaba y Attacum estaba aún sin reducir. ${ }^{12}$ La ubicación en El Tolmo coincide con la descripción de Ptolomeo, y como tal ha sido identificada desde tiempo atrás, aunque en la mayor parte de las ocasiones lo ha sido con la actual Hellín. Sillières propuso ya su ubicación con argumentos arqueológicos en El Tolmo de Minateda, ${ }^{13}$ localización que han reforzado los estudios toponímicos. Según diversos especialistas, el tránsito de Ilunum a Eio, nombre atestiguado en época visigoda, de Eio a Madinat Iyuh, nombre árabe atestiguado en al Udri, de Madinat Iyuh a Medinatea, conocido en documentos medievales, y desde este al topónimo actual, Minateda, la aldea inmediata al yacimiento, es bastante plausible. ${ }^{14}$

Interesante es también reflexionar acerca de dónde se encontraba la inscripción. En un primer momento, y puesto que los sillares aparecían caídos desde un muro,

12 ALFÖLDY 1977, 91-93.

13 SiLliÈres 1982, 247-248.

14 Esta cadena de transmisión ha sido propuesta y aceptada por varios autores y es la que defiende el equipo de investigación (Molina 1971, 73; GutiérRez Lloret 2000, 481-502; AbAD - GutiÉrREZ - GAMO- CÁNOVAS 2012, 354 y especialmente nota 2). No obstante, es discutida por quienes defienden otras ubicaciones para el obispado de Eio / Elo. Una síntesis de estos argumentos en PeIDró 2008, 303-320 y PEIDRó 2008b, $263-276$. No nos referimos en extenso a este problema porque no resulta de interés para el caso que ahora nos ocupa. 
pensamos que su ubicación original habría sido el lienzo de la muralla. Pero pronto nos dimos cuenta de que los sillares estaban reaprovechados y que éstos, además, aparecían en las dos caras del muro que formaban una L, por lo que esta hipótesis se desechó pronto. Lo más probable es que el emplazamiento original estuviera sobre la puerta de entrada, seguramente arqueada. Nada se ha conservado de ella, pues el lugar fue desmontado y recortado en época visigoda para construir su propia puerta. Esta debió de estar en el mismo lugar o, lo que parece más probable, más retranqueada que la romana, para alargar el pasillo que quedaba entre el farallón septentrional del Reguerón y el brazo corto de la L, tanto por el retranqueo de la puerta como por el avance de la cara principal del baluarte. En estas condiciones habría que eliminar por completo la entrada más antigua, adosada al farallón septentrional, que quedaría fuera del nuevo recinto. De otra forma hubiera servido de refugio a los enemigos que subieran por el camino y se encontraran sometidos a un fuego cruzado desde el baluarte que quedaba a su derecha, desde lo alto de la puerta a su frente y desde el propio farallón a su izquierda.

Nuestra hipótesis es, pues, que el epígrafe estaba situado sobre la puerta de entrada. Sus dimensiones, unos $8 \mathrm{~m}$ de longitud por 1,5 de alto, convienen a la medida del camino actualmente conservado, de época visigoda, aunque no sabemos si éste coincide total o parcialmente con el que estuvo en uso en época romana.

En el paramento de la torre visigoda se encontró otro epígrafe, con la cara escrita hacia arriba. Sus letras son similares a las de la monumental, aunque más pequeñas e irregulares y no tienen ese carácter. En ella se menciona a tres individuos, uno primero, $T \cdot$ Martius, y dos a continuación, $G \cdot$ Grattius Grattianus y $V \cdot$ Fulvius Ovetus, que aparecen como IIviri, sin indicar por desgracia el nombre de la ciudad. Al final, la abreviatura de $H \cdot O \cdot F \cdot C$, que ya en su momento interpretamos como hoc opus faciendum curaverunt. Queda descolgado el primer nombre, para el que propusimos una prefectura individual como encargado de organizar la municipalización de la ciudad. ${ }^{15}$

La ciudad de Ilunum, que recibe su estatuto municipal a fines del año 9 a.C., y lo celebra con un muro que ennoblece la vista de la ciudad desde el camino de Complutum a Carthago Nova que pasaba a sus pies, no tuvo una vida muy larga. En los lugares en los que hasta el momento se ha excavado hemos encontrado cremaciones tardorrepublicanas y altoimperiales en la necrópolis norte y material tardorrepublicano en los intersticios de la roca original de la plataforma superior, recortada en el momento en que los visigodos erigieron su conjunto episcopal. Hay numerosos vestigios de monumentos funerarios y algunos de monumentos religiosos o de representación, pero ninguno de ellos se ha encontrado in situ. Da la impresión de que la ciudad languideció a lo largo del siglo I de nuestra era, al tiempo que sus habitantes bajaban al llano y se establecían en los ricos asentamientos de alrededor. Los más destacados de entre los conocidos, el ya citado de Zama y la villa de Hellín, de donde procede el magnífico mosaico del calendario que se conserva en el Museo Arqueológico Nacional y donde recientemente se ha encontrado una instalación termal. Sin

15 ABAD 1996, 96. 
embargo, algunas inscripciones encontradas en las últimas campañas, fragmentadas y fuera de contexto, indican que la ciudad siguió existiendo y albergó vida durante todo este tiempo. ${ }^{16} \mathrm{Su}$ resurgimiento se alcanzará en época visigoda, cuando adquiere un papel principal en el marco de las guerras grecogóticas y se erige en obispado. ${ }^{17}$ Pero esa es ya otra historia.

\section{BibLIOGRAFÍA}

Abad CASAL, L.

(1996): "La epigrafía romana de El Tolmo de Minateda (Hellín, Albacete) y un nuevo municipio romano del Conventus Carthaginensis", Archivo Español de Arqueología 69.

(2006): "The juridical promotion of oppida of the southeast of the Iberian peninsula: the cases of Ilici and Ilunum", [en] Early Roman Towns in Hispania Tarraconensis, (=Journal of Roman Archaeolgy Supplementary Series 62), Rhode Island.

Abad Casal, L. - Abascal Palazón, J. M. (2010): "Nuevas inscripciones de El Tolmo de Minateda (Minateda, Albacete, Hispania citerior)", Mastia 9.

Abad Casal, L. - Abascal Palazón, J. M. - Sanz Gamo, R. (2002): “Monumentos funerarios romanos de época romana en la provincia de Albacete”, [en] R. Sanz Gamo (coord.), II Congreso de Historia de Albacete, Arqueología y prehistoria Vol. I, Albacete.

Abad Casal, L. - Gutiérrez Lloret, S. - Gamo Parras, B. - Cánovas Guillén, P. (2012): "El Tolmo de Minateda (Hellín, Albacete, España): un proyecto de investigación y puesta en valor del patrimonio", Debates de Arqueología Medieval 2.

Abad Casal, L. - Gutiérrez Lloret, S. - Sanz Gamo, R. (1998): El Tolmo de Minateda. Una historia de 3500 años, Toledo.

Abad Casal, L. - Sanz Gamo, R. (2012): "El Tolmo de Minateda (Hellín, Albacete). Una ciudad en el camino a Carthago Nova", [en] G. Carrasco (coord.), La ciudad romana en Castilla-La Mancha, Ciudad Real.

AlarcÂO, J. DE (1991): “A urbanizaçao de Portugal nas épocas de César e de Augusto”, [en] Stadtbild und Ideologie. Die Monumentalisierung hispanischer Städte zwischen Republik und Kaiserzeit, München.

ALFÖLDY, G.

(1977): Römisches Staädtewesen auf der neukastilischen Hochebene Ein Testfall für die Romanisierung. Heidelberg.

(2007): "Fasti und Verwaltung der hispanischen Provinzen: zum heutigen Stand der Forschung”, [en] R. Haensch - J. Heinrichs (eds.), Herrschen und Verwalten. Den Alltag der römischen Administration in der Hohen Kaiserzeit, Köln.

BACCHIELLI, R. (1984): "Le porte romani ad ordine sovraposti e gli antecedenti greci”, Römische Mitteilungen 91.

GutiÉrRez Lloret, S. (2000): “La identificación de Madinat Iyih y su relación con la sede episcopal elotana. Nuevas perspectivas sobre viejos problemas", [en] Studia in honorem Enrique A. Llobregat Conesa, Alicante.

16 Abascal - Abad 2010, 207-220.

17 Gutiérrez Lloret 1999, 101-128, Vizcaíno 2007, 117-119, VizCAíno 2009, 211-215. 
Gutiérrez Lloret, S. (1999): "La ciudad en la antigüedad tardía en el Sureste y Levante", [en] La reviviscencia urbana en el marco del conflicto grecogótico. Complutum y las ciudades hispanas en la antigüedad tardía, Alcalá de Henares.

Gutiérrez Lloret, S. - AbAd CASAL, L. (2002): "Fortificaciones urbanas altomedievales de El Tolmo de Minateda (Hellín, Albacete, España), el baluarte occidental”, [en] Mil Anos de Fortificações na Península Ibérica e no Magreb (500-1500); Actas do Simpósio Internacional sobre Castelos, Lisboa.

Molina LóPez, E. (1971): "Iyyu(h): otra ciudad yerma hispano-musulmana”, Cuadernos de Historia del Islam 3.

Noguera Celdrán, J. M. (1994): La escultura romana en la provincial de Albacete (Hispania Citerior - Conventus Carthaginensis), Albacete.

Peidró Blanes, J.

(2008): "La política administrativo-religiosa del estado visigodo en el Sureste: el caso de la creación de la sede espiscopal Elotana", Espacio, Tiempo y Forma, Serie II, Historia Antigua 21.

(2008b): "La región de la Oróspeda tras Leovigildo. Organización y administración del territorio", Verdolay 11, 263-276.

RebecchI, F. (1985): “Les enceintes augustéennes dans l'Occident romain” (France, Italie, Espagne, Afrique du Nord)", [en] Actes du Coloque International de Nimes, III Congrès Archéologique de Gaule Méridionale, 1985, (=Bulletin Annuel de l'École Antique de Nimes 18).

Rodríguez-Pascua, L. - Abad Casal, L. - Pérez lópez, R. - Gamo Parra, B. - Silva, P. G. - Garduño-Monroy, V. H. - Giner-Robles, J. L. - Israde Alcántara, J. - Bischoff, J. - CAlvo, J. P. (2009): "Roman, visigothic and islamic evidence of earthquakes recorded in the Archaeological site of 'El Tolmo de Minateda (Prebetic zone, Southeast of Spain)", [en] 1st INQUA-IGCP internacional Workshop on Earthquake Archaeology and Palaeosesmology), Baelo.

Rodríguez-Pascua, M. A. - Silva, G. P. - Garduño-Monroy, V. H. - Pérez-López, R. Israde-Alcántara, I. - Giner-Robles, J. L. - Bischoff, J. L. - Calvo, J. P. (2010): “Ancient earthquakes from arcaheoseismic evidence during the Visigothic and Islamic periods in the archaeological site of 'Tolmo de Minateda' (SE Spain)", The Geological Scociety of America. Special Paper 471.

Schattner, T. G. (2006): “Die 'Puerta de Sevilla' en Carmona und andere römische Stadtore auf der Iberischen Halbinsel”, [en] T. G. Schattner - F. Valdés Fernández (eds.), Stadttore. Bautyp und Kunstform, Toledo.

SCHUlze, R. (1909): “Die römischen Stadttoren”, Bonner Jahrbücher 118.

Sillières, P. (1982): “Une grande route romaine menant a Carthagène: la voie Saltigi-Carthago Nova", Madrider Mitteilungen 23.

VizCAÍNO SÁNCHEZ, J.

(2007): "La presencia bizantina en Hispania (siglos VI-VII). La documentación arqueológica", Antigüedad y Cristianismo 24.

(2009): La presencia bizantina en Hispania, siglos VI-VII: la documentación arqueológi$c a$, Murcia. 